\title{
PERENCANAAN TATA LETAK FASILITAS PADA PRODUK TROLLEY
}

\author{
Ade Astuti Widi Rahayu' ${ }^{1}$, Aris Insan Waluya², Ragil Yuli Santosa ${ }^{3}$, Abu \\ Jaelani $^{4}$, Fajar Maulana Sodik ${ }^{5}$, Nunu Nugraha ${ }^{6}$, Rizky Jaenudin ${ }^{7}$ \\ 1,2,3,4,5,6,7 Jurusan Teknik Industri, Fakultas Teknik dan Ilmu Komputer, Universitas Buana Perjuangan \\ Karawang \\ Jl. HS. Ronggowaluyo Telukjambe Timur Karawang, \\ Email: ade.widiastuti@ubpkarawang.ac.id
}

\begin{abstract}
Layout is one of the most important things in a company in designing the needs and facilities that support a business and production process. The purpose of this study was to make a facility layout plan for the trolley assembly practicum at the Production and Manufacturing Systems Laboratory, Universitas Buana Perjuangan Karawang. The method used in this study uses the blocplan algorithm analysis method. Based on the results of the research that has been carried out, making part drawings and operation process charts are used to obtain an accurate and unambiguous description of the geometric features of a component and obtain an overview of the plant layout requirements obtained based on the needs of raw materials, machines, and the efficiency of each operating process and examination, while activity relationship chart analysis, blocplan algorithm analysis and area allocation diagram analysis were used to determine a detailed description or layout template for factory facilities in the hope of optimizing productivity and reducing company losses.
\end{abstract}

Keyword: algorithm blocplan; production facility; layout.

\begin{abstract}
ABSTRAK
Tata letak merupakan salah satu hal yang sangat penting dalam suatu perusahaan dalam merancang kebutuhan dan fasilitas yang mendukung suatu proses bisnis dan produksi. Tujuan dari penelitian ini adalah membuat suatu perencanaan tata letak fasilitas pada praktikum perakitan trolley di Laboratorium Sistem Produksi dan Manufaktur Universitas Buana Perjuangan Karawang. Metode yang digunakan dalam penelitian ini menggunakan metode analisis algoritma blocplan. Berdasarkan hasil penelitian yang sudah dilakukan, pembuatan part drawing dan operation process chart digunakan untuk memperoleh gambaran fitur geometrik yang akurat dan tidak ambigu dari sebuah komponen dan memperoleh gambaran kebutuhan tata letak pabrik yang didapat berdasarkan kebutuhan bahan baku, mesin, serta efisiensi tiap proses operasi dan pemeriksaan, sedangkan analisis activity relationship chart, analisis algoritma blocplan dan analisis area allocation diagram digunakan untuk menentukan gambaran detail atau template tata letak fasilitas pabrik dengan harapan dapat mengoptimalkan produktivitas dan mengurangi kerugian perusahaan.
\end{abstract}

Kata Kunci: algoritma blocplan; fasilitas produksi; tata letak.

\section{PENDAHULUAN}

Perkembangan dunia industri di Indonesia semakin tahun semakin berkembang pesat. Hal ini didukung dengan adanya kebijakan pemerintah dalam memberikan kemudahan kepada investor asing untuk menanamkan modal dan berinvestasi diberbagai sektor usaha di Indonesia termasuk sektor industri. Berdasarkan perkembangan industri yang ada di Indonesia, muncul suatu peluang usaha dimana untuk mendirikan suatu perusahaan dan gedung operational baru akan membutuhkan jasa dari perusahaan jasa konstuksi yang akan membuat perencanaan tata letak dan fasilitas perusahaan. Hal ini bertujuan agar perusahaan yang akan di bangun dapat 
berjalan secara optimal dan sesuai dengan harapan.

Pada praktikum perencanaan tata letak fasilitas kali ini, para Praktikan mendapatkan tugas untuk menyusun suatu rencana proyek pembangunan perusahaan baru yang bergerak dibidang perakitan trolley. Perusahaan perakitan trolley ini ingin membangun suatu pabrik di kabupaten Karawang. Berdasarkan hal tersebut kelompok Mahasiswa yang bertanggung jawab sebagai pihak konstruksi merekomendasikan pembangunan gedung pabrik perakitan trolley ini di Kawasan Industri Mitra atau KIM. Berdasarkan proyek pembangunan pabrik perakitan trolley ini maka perlu dilakukan suatu perencanaan tata letak fasilitas pabrik secara berkelanjutan dengan metode dan teknologi yang sesuai agar dapat memaksimalkan fungsi, mengurangi kerugian dan keberlangsungan perusahaan di masa depan.

\section{METODE PENELITIAN}

Berikut merupakan langkah-langkah dari alur penelitian ini yang akan di jelaskan dalam bentuk gambar.

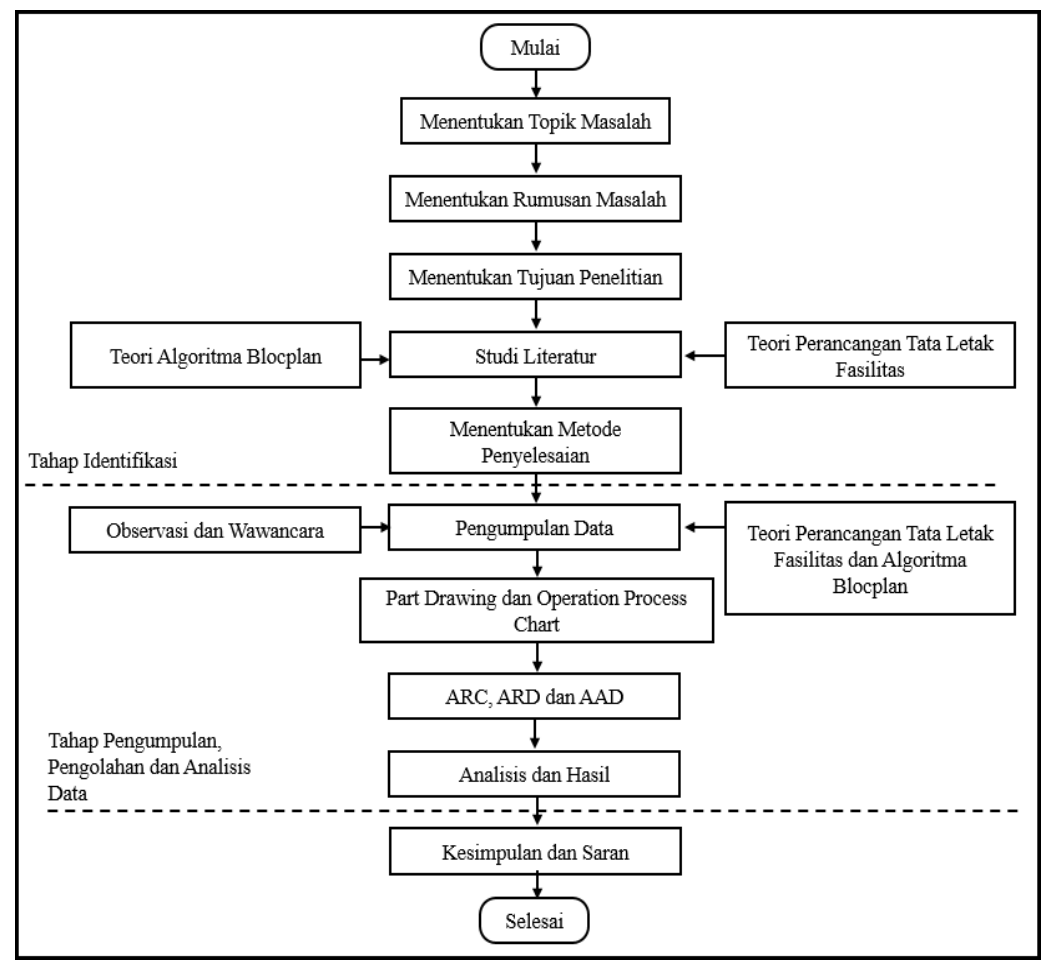

Gambar 1. Flow Chart Penelitian

\section{HASIL DAN PEMBAHASAN}

Langkah pertama dalam penelitian ini adalah membuat part drawing atau menggambar material-material yang digunakan dalam perakitan trolley. Gambar ini dibuat dengan tujuan memberikan gambaran fitur geometrik yang akurat dan tidak ambigu dari sebuah komponen. Dengan demikian, gambar teknik memberikan seluruh informasi yang dibutuhkan oleh manufaktur untuk memproduksi komponen tersebut. 

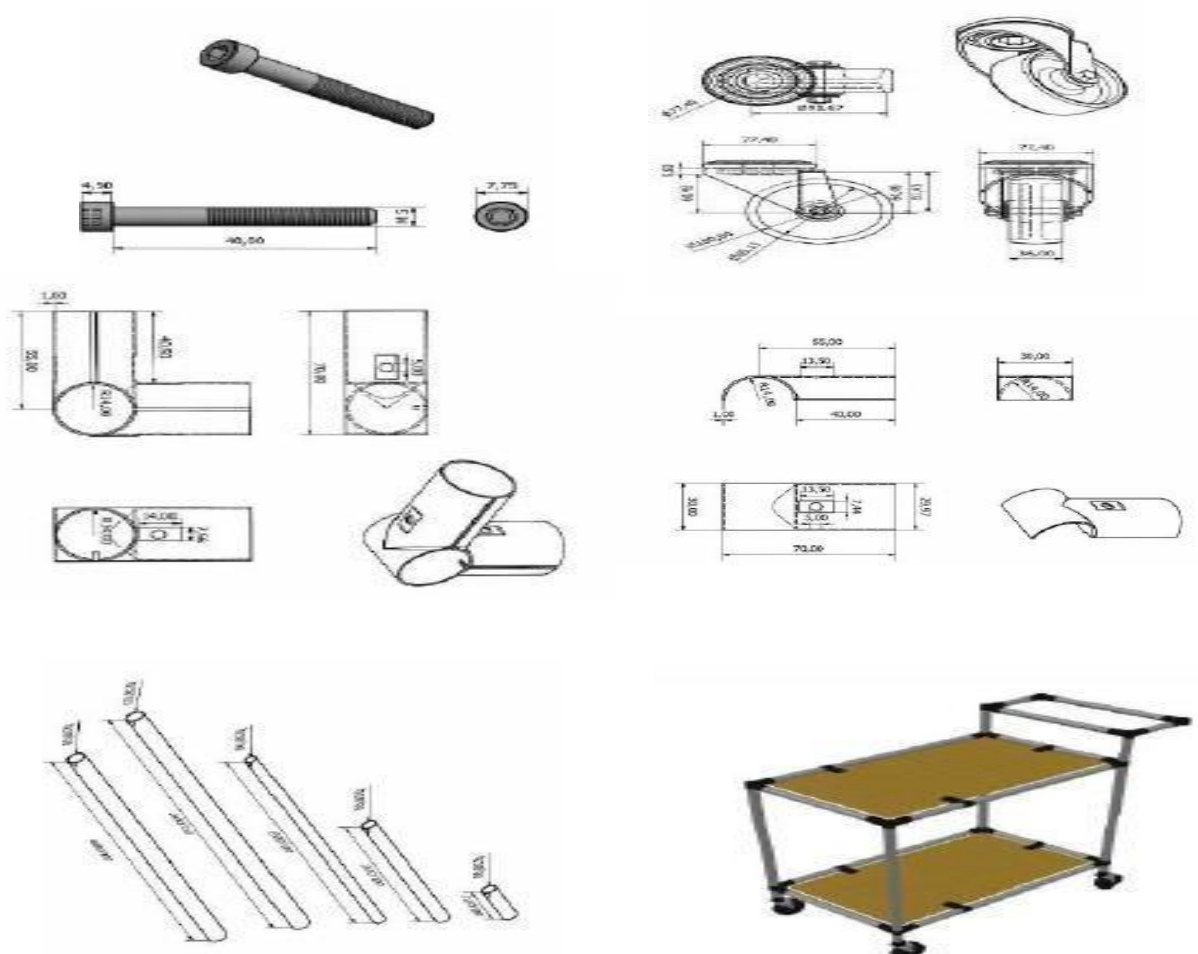

Gambar 2. Part drawing komponen trolley

\section{Analisis Activity Relationship Chart (ARC)}

Setelah melakukan pembuatan part drawing dan operation process chart, langkah selanjutnya adalah melakukan analisis activity relationship chart. Pada analisis ini didapat berdasarkan deskripsi alasan hubungan aktivitas dan derajat hubungan. Berikut merupakan hasil analisis activity relationship chart (ARC) beserta deskripsi alasan hubungan aktivitas dan derajat hubungan yang digunakan pada penelitian ini.

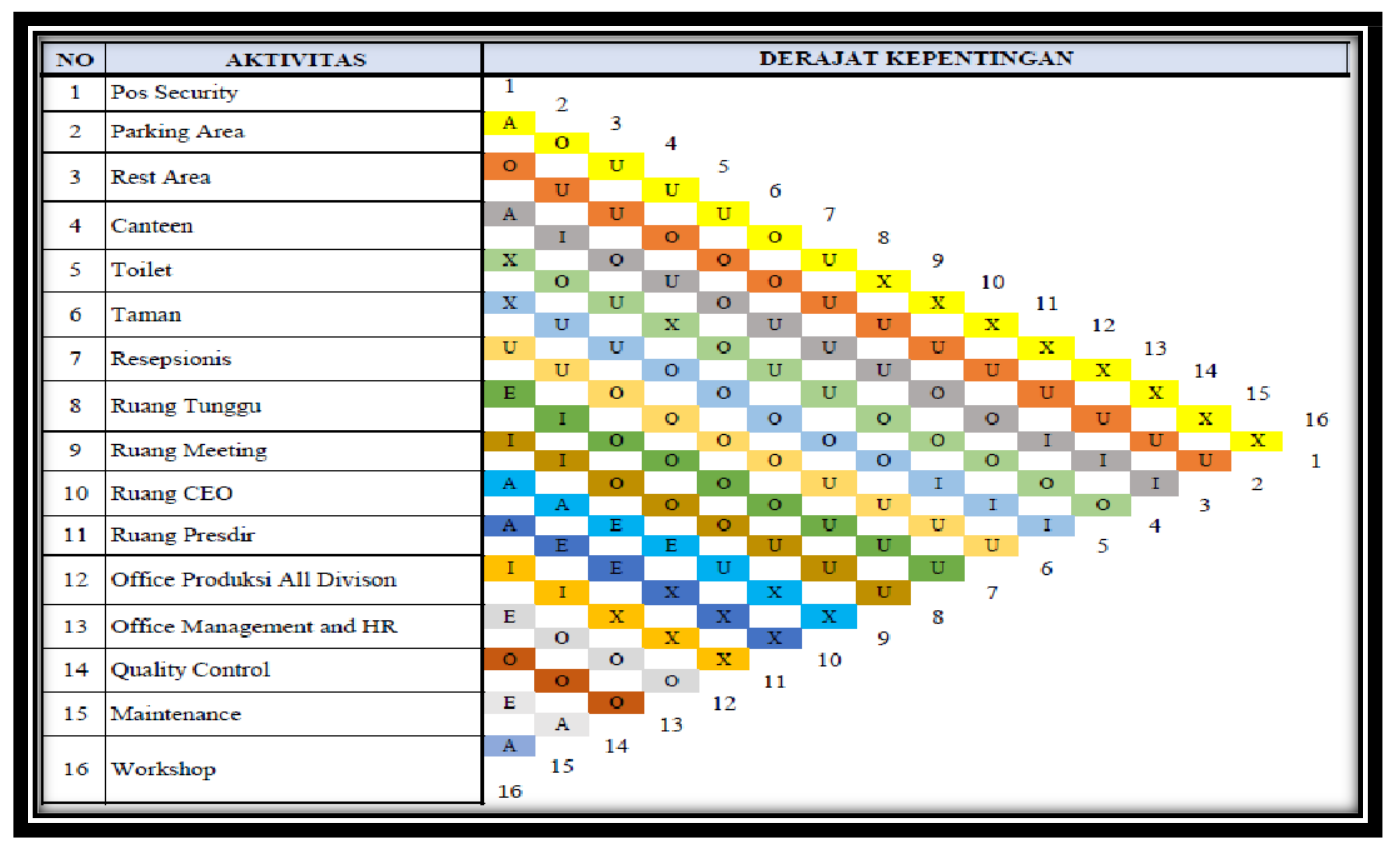

Gambar 3. Activity Relationship Chart 


\section{Analisis Algoritma Blocplan}

Proses selanjutnya setelah melakukan analisis ARC adalah melakukan analisis data dengan menggunakan software algoritma blocplan. Langkah pertama dalam analisis ini adalah dengan memasukan nilai hubungan kedekatan antar departemen berdasarkan ARC yang telah dibuat, masukkan nilai vektor dengan menggunakan angka default blocplan, masukkan rekapitulasi skor tiap departemen yang dihitung berdasarkan nilai vektor default dari blocplan, kemudian pilih rasio perbandingan layout, disini digunakan SEL 1 (1:1.35), pada main menu, pilih 3. Single Story Layout, pada menu Single Story, pilih opsi nomor 4. Automatic Search, memasukkan jumlah opsi berupa output layout, disini digunakan 5 opsi layout. kemudian akan keluar tampilan seperti berikut :

Berdasarkan data pada analisis diatas terlihat bahwa dari ke 5 opsi layout terdapat nilai ADJ Score atau nilai kedekatan hubungan antar fasilitas yang ada pada perusahaan, secara teori layout yang harus dipilih adalah layout yang memiliki nilai ADJ Score paling besar atau mendekati 1, maka dari itu layout yang dipilih adalah layout 2 dengan nilai ADJ sebesar 0,65.

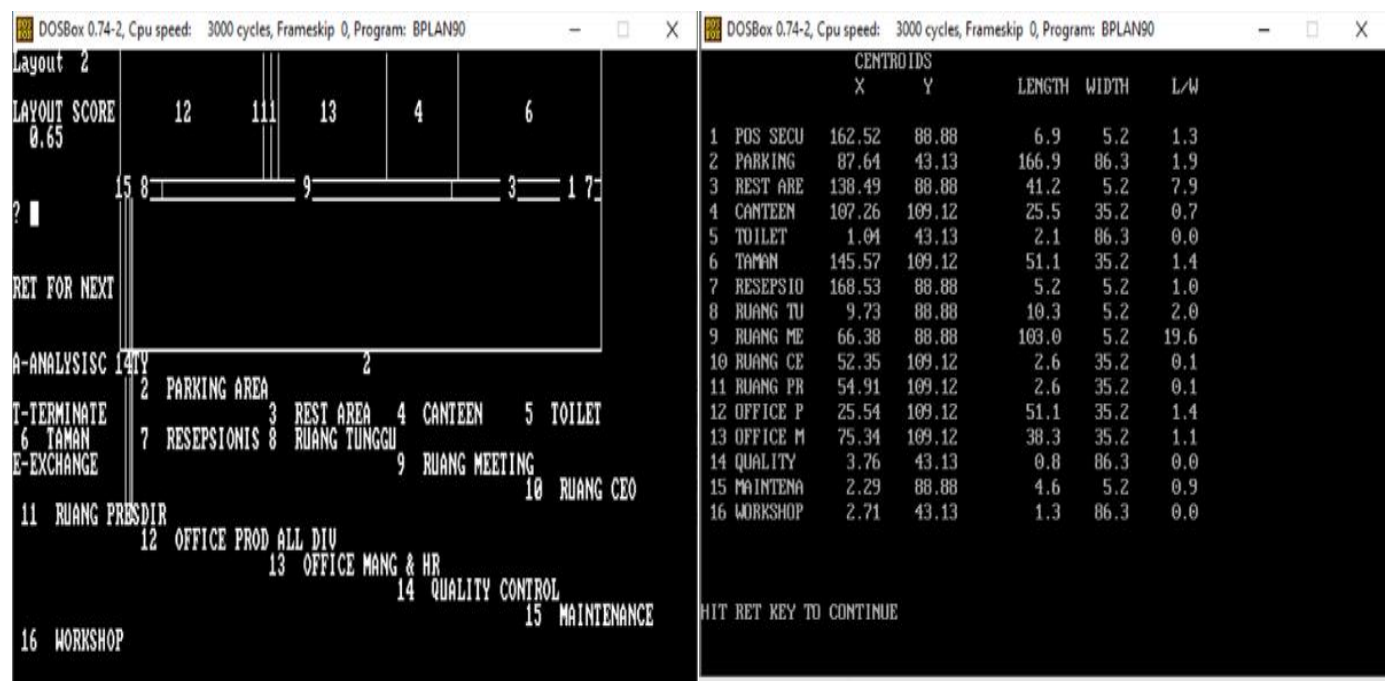

Gambar 4. Layout terpilih dan Rincian Luasnya

Berikut merupakan gambaran detail atau template dari area allocation diagram dari tata letak fasilitas pabrik dengan menggunakan software autocad.

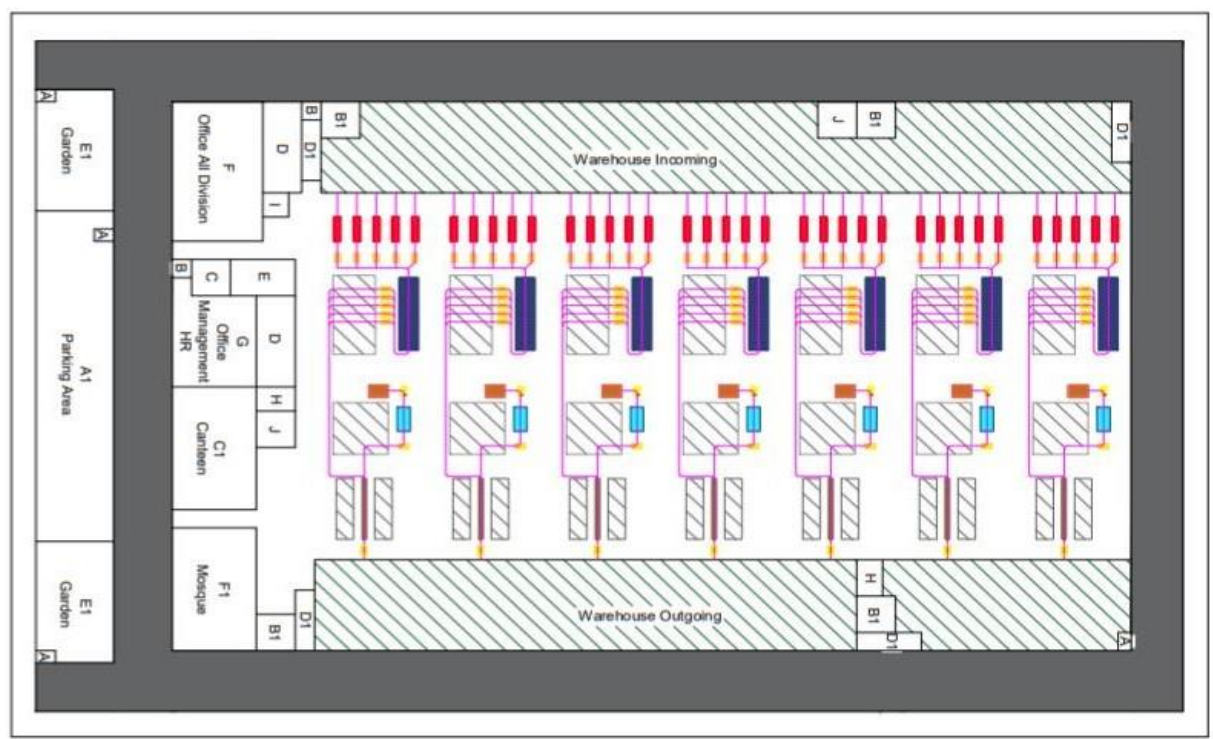

Gambar 5. Template Rencana Pabrik 


\section{KESIMPULAN}

Berdasarkan hasil analisis dan pembahasan pada penelitian ini maka dapat disimpulkan bahwa pembuatan part drawing dan operation process chart digunakan untuk memperoleh gambaran fitur geometrik yang akurat dan tidak ambigu dari sebuah komponen dan memperoleh gambaran kebutuhan tata letak pabrik yang didapat berdasarkan kebutuhan bahan baku, mesin, serta efisiensi tiap proses operasi dan pemeriksaan. Analisis activity relationship chart, analisis algoritma blocplan dan analisis area allocation diagram digunakan untuk menentukan gambaran detail atau template tata letak fasilitas pabrik dengan harapan dapat mengoptimalkan produktivitas dan mengurangi kerugian perusahaan.

\section{DAFTAR PUSTAKA}

Apple, James M. (1990). Tata Letak Pabrik dan Pemindahan Bahan, Edisi ke Lima.

Bandung : Institut Teknologi Bandung.

Arif, Muhammad. (2017). Perencanaan Tata Letak Fasilitas, Cetakan Pertama.

Sleman : Penerbit CV Budi Utama.

Rahayu, Ade Astuti Widi. (2020). Modul Praktikum Perencanaan Tata Letak Fasilitas.

Karawang: UBP Karawang.

Wignjosoebroto, Sritomo. (2009). Tata Letak Pabrik dan pemindahan Bahan, Edisi Ketiga.

Surabaya: Penerbit Guna Widya. 